\title{
Analyzing Convergence and Synchronicity of Business and Growth Cycles in the Euro Area using Cross Recurrence Plots ${ }^{12}$
}

\author{
Patrick M. Crowley ${ }^{3}$
}

April 2008

\footnotetext{
${ }^{1}$ Acknowledgements: The Bank of Finland are to be thanked for hosting the author during the summers of 2006 and 2007 where much of this work was originally done. The author acknowledges the valuable comments from participants at the Bank of Finland Macro Workshop (August 8th, 2007) and the 2nd Recurrence Plot Workshop in Siena, Italy (Sept 12-14th, 2007). The author would also like to thank Aaron Schultz for programming assistance, Joe Zbilut, Norbert Marwan, Mikael Bask for advice on recurrence plot techniques and Tero Kuusi for data assistance. ${ }^{2}$ Paper currently under revise and resubmit for Physica D.

${ }^{3}$ College of Business, Texas A and M University - Corpus Christi, 6300 Ocean Drive, Corpus Christi, TX 78412, USA. email: patrick.crowley@tamucc.edu
} 


\begin{abstract}
Convergence and synchronisation of business and growth cycles are important issues in the efficient formulation of euro area monetary policy by the European Central Bank (ECB). Although several studies in the economics literature address the issue of synchronicity of growth within the euro area, this is the first study to address this issue using cross recurrence analysis. The main findings are that member state growth rates have largely converged since the introduction of the euro, but there is a wide degree of different synchronisation behaviours.which appear to be non-linear in nature. These differences could cause problems in future implementation of a single (ECB-determined) monetary policy in the euro area.
\end{abstract}




\section{Introduction}

The macroeconomy of the market-based economic system is probably the largest man-made complex system in existence. Although economists have created a large arsenal of time-series techniques to analyze the movement of macroeconomic variables over time, these models come with a host of assumptions (for example linearity, disributional assumptions, constant parameters) and so have limited ability to detect and characterise the non-linearities inherent in this system. Although a cycle in economic activity is a "stylized" fact in macroeconomics, it is less clear as to when the economic growth dynamic coincides between countries and when these dynamics synchronise. It is well known that the recessionary phase of the business cycle in most countries appears to closely follow downturns in the US economy, but often there is a variable lag to this effect, and sometimes it does not occur ( - for example the euro area in the early 2000s).

In economics, Gross Domestic Product (GDP) is used to measure of the size of the macroeconomy, but given that this variable is non-stationary and measured using current prices, the main metric for economic expansion that economists use to assess the rate of growth of the macroeconomy is the change in real (inflation-adjusted) GDP over time ("economic growth"), and this is the statistic that is used by policymakers and reported in the financial media. It is widely recognized that fluctuations in the growth of real GDP exhibits cycles, and the most important of these occurs when economic growth becomes negative ( - in other words the size of the economy shrinks), and this is known as the "business cycle", but these

cycles are acknowledged as being asymmetric, inconsistent in their severity and occur at irregular intervals of usually between 3 and 10 years.

For a large country or several countries using the same currency, dissimilar economic growth dynamics pose a potential problem for the implementation of a single monetary policy as economic conditions may vary across the country (as with the varying performance of US states) or across several countries using the same currency (as for example with the euro area), leading to problems in setting monetary policy (which regions or countries have more or less weight in economic aggregates used in the monetary policy decisionmaking process) and consequent issues in terms of the suitability of monetary policy actions for regions or countries at different phases of the business cycle. The establishment of the euro area in 1999 brought this issue to the fore, as economists recognized that a common monetary policy administered by the European Central Bank (ECB) might prompt both convergence and greater synchronicity in business cycle variables (perhaps to the extent that economic growth has converged and synchronized between the US states).

According to the celebrated optimal currency area theory (Mundell (1961)), within a monetary union, given the absence of labor mobility and federal transfers as offsetting economic factors, synchronicity of growth cycles is an important pre-requisite for the optimal application of a single monetary policy. This clearly becomes an important issue for the efficacy of monetary policy as well as the establishment of policy 
initiatives to offset any sub-optimality of monetary policy due to lack of convergence or synchronicity.

Given the fact that business cycles are to a great extent the only cycle that economists recognize in national income data, it is perhaps natural to study the synchronicity of these cycles, and yet for monetary policy the dynamic of real GDP growth at other frequencies is also important. As monetary policy usually operates at roughly a monthly level, the dynamic of real GDP growth at even quarterly frequencies has implications for the implementation of monetary policy across different countries or jurisdictions. Because synchronisation of business and growth cycles is an important consideration for operation of a single currency, monetary policy is more easily formulated if these cycles in real GDP growth (business cycle or otherwise) are similar between the member states that qualified and subsequently adopted the euro.

The main purpose of this paper is to illustrate how recurrence plots can be applied to an important macroeconomic issue, in order to shed light on the non-linear dynamics present in a complex economic system. The technique of recurrence plot analysis is used to analyse both convergence and synchronisation of economic growth, at all cycle frequencies. Recurrence plot analysis is now over 20 years old (see Eckmann, Kamphorst, and Ruelle (1987) for the first contemporary application) and the quantification of these plots is much more recent (see Zbilut and Webber Jr. (1992) and Webber and Zbilut (1994)) but the notion of recurrence has a much longer pedigree in mathematics (see Feller (1950)). Recurrence plots first originated from work done in mathematics and physics but now has a considerable following in a variety of fields ${ }^{1}$. There are several excellent introductions available to RQA and recurrence plots, not least those by Marwan, Romano, Thiel, and Kurths (2007) and Webber Jr. and Zbilut (2005). In this paper two illustrative examples of the use of recurrence plots are presented, first showing the propagation of business cycles from the US to the euro area, and then secondly the synchronicity of business and growth cycles within the euro area is studied. There are very few papers that apply recurrence plot techniques to macroeconomic issues, the notable exceptions being Zbilut (2005) and Kyrtsou and Vorlow (2005), and neither of these papers look at cross recurrence or these particular issues.

\section{Business and growth cycles and the euro area}

There has long been recognition of the propagation of business cycles between countries ( - the main mechnanisms being trade and capital flows). The main indicator of this propagation is the synchronicity of turning points in business cycles (noted by Backus and Kehoe (1992) and Backus, Kehoe, and Kydland (1995) in the real business cycle literature) but what is not recognized is that the economic growth dynamic between these turning points (usually the recessions or peaks of business cycles) can be radically different between countries. This observation has given rise to the notion and study of growth cycles in the context

\footnotetext{
${ }^{1}$ Norbert Marwan's website catalogues all the articles published using recurrence plots and RQA, and is a veritable mine of information on this topic. See http://www.recurrence-plot.tk
} 
of the dynamic of economic growth between these turning points (see Kontolemis (1997) and Zarnowitz and Ozyildirim (2002)). From an empirical perspective there have been some efforts to empirically extract these cycles for measurement and comparison across countries using other time-frequency techniques (see ?), Crowley and Lee (2005) and Crivellini, Gallegati, Gallegati, and Palestrini (2004)) but only limited research has been conducted in this area.

In the euro area context, there has been a recognition for some time that with closer cooperation in monetary policy, firstly under the exchange rate mechanism (ERM) of the European Monetary System (EMS) and the run up to Economic and Monetary Union (EMU), and then secondly during the shift to the adoption of the euro within the EMU process ( - using specified economic convergence criteria), that synchronisation of euro area growth rates would likely increase. But measuring this has been more problematic for a variety of reasons - notably the short data span available and the exceptional circumstances surrounding events in the early part of this decade (9/11, Iraq invasion, German structural problems etc). Despite these issues, there has been a variety of empirical research of different types done on this topic, with notable contributions by Artis and Zhang (1997) who first recognized the existence of a separately identifiable European business cycle, followed by Artis and Zhang (1999), and then mostly studies that have tried to measure whether the "European business cycle" has become stronger since the inception of EMU and the introduction of the euro and a single monetary policy (see Altavilla (2004), Sensier, Artis, Osborn, and Birchenhall (2004), Valle e Azevedo (2002), De Haan, Inklaar, and Sleijpen (2002), and Süssmuth (2002)).

This is an important issue for the ECB for a myriad of reasons. First, the OCA theory suggest that similar growth rates in member states will ease the problems associated with the differential impact of monetary policy on these countries. Second, not only do growth rates matter, but also the dynamics of growth also matters - thus the idea that similar frequency growth cycles between countries in a monetary union will also ease the problems of implementing monetary policy across a collection of member states or countries. Third, OCA theory also suggests that even without this increased synchronicity of business and growth cycles, increased mobility of factors of production can counter this and so aid implementation of monetary policy as resources can flow from one country to another to offset the differential impact of monetary policy. With the advent of the single market in the EU after 1992, labor and capital mobility have increased, but it is still widely acknowledged that language and cultural barriers impose greater barriers to mobility of factors of production than they do in many other monetary unions (such as the US or Canada). Fifth, another offset to lack of synchronisation can be found in autonomy of fiscal policy, perhaps at a national or member state level, or at the supra-national level. This has caused considerable concerns in the euro area in past years, as the Stability and Growth pact (SGP) appeared to severely limit member state fiscal policy so as to counterbalance ECB monetary policy and its differential impact on certain 


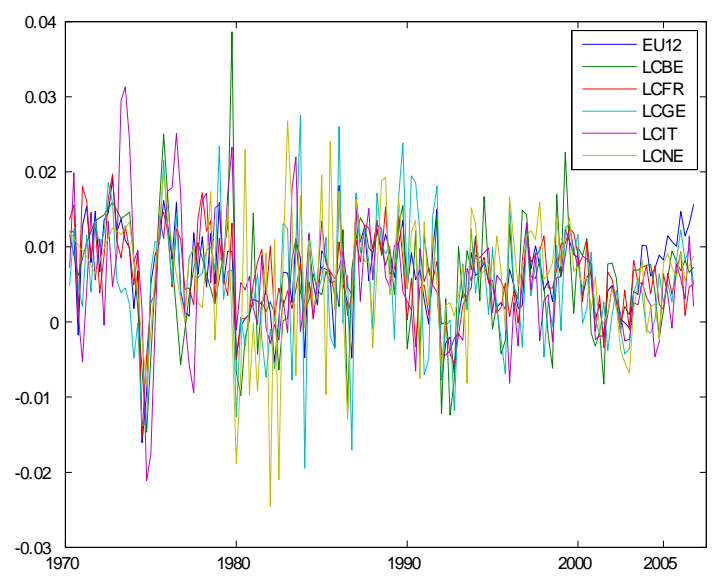

Figure 1: Selected core euro area member state growth rates (quarterly log change in real GDP)

member states, dependent largely on debt levels and any existing structural budget deficit considerations ( - for example Germany). Lastly, there is also a feedback effect involved, as a single monetary policy should impact all member state growth rates across the euro area implying that an OCA might be created endogenously ( - see Frankel and Rose (1998)).

\section{Data and embedding}

\subsection{Data}

Given that real GDP is non-stationary, the main metric for economic growth that economists use to assess the rate of growth is the change in real (inflation-adjusted) Gross Domestic Product (GDP) over time. Here, in order to analyse economic growth, quarterly real GDP data was used.transformed into log quarter over quarter changes ${ }^{2}$. The data used in this study was sourced from a variety of different national statistical offices, while the euro area aggregate was obtained from the ECB's euro area quarterly model database ${ }^{3}$ and updated using Eurostat. The transformed data runs from 1971 quarter 2 (1971Q1) through 2007 quarter 1 (2007Q1) giving 147 datapoints.

Figure 1 shows the data for selected core euro area member states - then peripheral euro area and non-euro area member state growth rates are shown in figure 2. Lastly, in figure 3 US growth is shown together with the euro area aggregate growth rate.

It should be noted that the growth rates of the EMU core countries are very similar and since the

\footnotetext{
${ }^{2}$ In mathematical terms, $g_{t}=\log \left(y_{t}\right)-\log \left(y_{t-1}\right)$, where $g_{t}$ is economic growth and $y_{t}$ is real GDP at time (measured in quarters) $t$. This is the conventional measure of economic growth for empirical macroeconomic research.

${ }^{3}$ This data can be obtained from the Euro Area Business Cycle Network at www.eabcn.org
} 
Euro area recurrence 4-2008

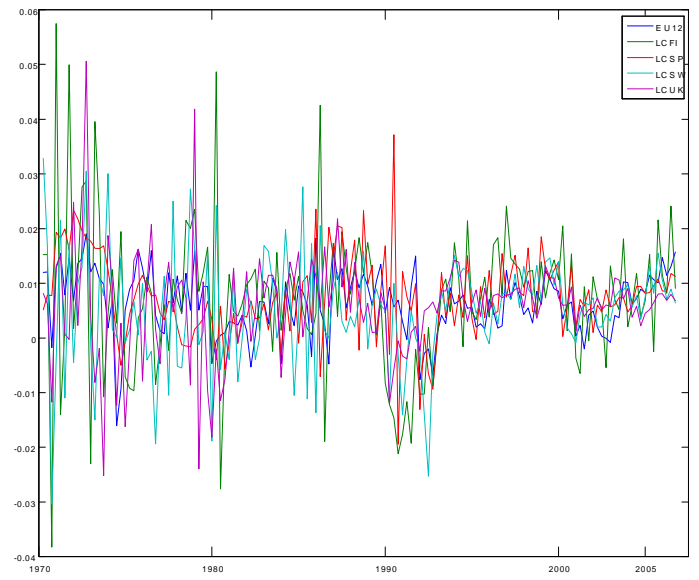

Figure 2: Selected periphery euro area and non-euro area EU member state growth rates (quarterly log change in real GDP)

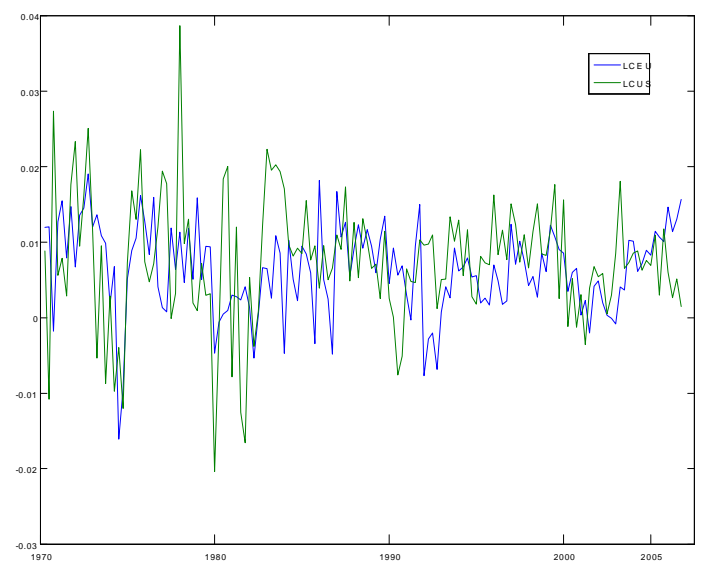

Figure 3: EU-12 aggregate and US growth rates (quarterly log change in real GDP) 
inception of EMU appear to be even less dispersed. With the peripheral EMU members the dispersion is much greater although since the early 1990s (coincident with the establishment of convergence criteria for membership of EMU) the growth rates have become more tightly bunched. In economic terms the dynamics of economic growth in European Union (EU) countries is going to be affected according to the time period under consideration - the pre-EMU exchange rate mechanisms ("snake", early EMS, "new" EMS) and the situation post-ERM crisis in 1993 through to full-blown EMU can all be thought of as different institutional regimes. Lastly there are significant similarities and differences between euro area growth cycles and those of the US - sometimes recessions are synchronised (for example in 1974 because of the common oil price shock) but in other instances recessions seem not to be phase synchronised (for example in the early 1990s).

\subsection{Recurrence plots and recurrence quantification analysis}

Using Takens' embedding theorem (see Takens (1981)), the recurrence plot is a way of analysing the dynamics of phase space trajectories in deterministic systems. Takens' embedding theorem states that the dynamics can be approximated from a time series $x_{k}$ sampled every $t$ by using an embedding dimension $m$, and a time delay, $\tau$, by a reconstruction of the phase-space trajectory $\vec{y}_{t}$, where:

$$
\vec{y}_{t}=\left(x_{t}, x_{t+\tau}, \ldots, x_{t+(m-1) \tau}\right)
$$

The choice of $m$ and $\tau$ are based on methods for approximating these parameters, such as the method of false nearest neighbors and mutual information for $m$ and $\tau$ respectively. When using cross recurrence plots, the choice of $m$ and $\tau$ are assumed to be the same.

Following Marwan, Thiel, and Nowaczyk (2002), the cross recurrence plot is definied by:

$$
\mathbf{C R}_{i, j}=\Theta\left(\varepsilon-\left\|y_{i}-z_{j}\right\|\right)
$$

where $i, j=1, \ldots, N, y_{i}$ and $z_{i}$ are two embedded series, $\varepsilon$ is the predefined "threshold", \|\| .is the norm (for example a Euclidean norm) and $\Theta$ is the Heaviside function. This gives a cross recurrence matrix $\mathbf{C R}_{i, j}$ which contains either zeros (the white areas in the plots) or ones.(the black areas in the plots). To get contoured plots, $\varepsilon$ is varied according to predetermined values. If the plot consisted of a single black line down the leading diagonal, then the two series would be identical. Obviously with empirical data this is unlikely so if dark lines appear which are offset from the main diagonal it implies phasing of the two dynamics.

Once the plot is obtained, measures can be derived to quantify the cross-dynamics of a given series. The distributions of the diagonal line lengths can be written as $P_{t}(l)$ for each diagonal parallel to the main diagonal, where $t=0$ denotes the main diagonal, $t>0$ denotes diagonals above the main diagonal (a lead) 
and $t<0$ denotes diagonals below the main diagonal (a lagged dynamic). Given this diagonal measure, the following measures can be extracted from the cross recurrence plot:

i) the recurrence rate

$$
R R(t)=\frac{1}{N-t} \sum_{l=1}^{N-t} l P_{t}(l)
$$

which represents the probability of similar dynamics occurring with delay $t$.

ii) a determinism measure

$$
\operatorname{DET}(t)=\frac{\sum_{l=l_{\min }}^{N-t} l P_{t}(l)}{\sum_{l=1}^{N-t} l P_{t}(l)}
$$

which represents the proportion of long sequences of dynamics in all similar dynamics. A deterministic system will have a high $D E T$ while a stochastic system will have a low $D E T$.

iii) average diagonal line length, $L(t)$ :

$$
L(t)=\frac{\sum_{l=l_{\min }}^{N-t} l P_{t}(l)}{\sum_{l=l_{\min }}^{N-t} P_{t}(l)}
$$

which shows the average duration of these similarities in the two series.

iv) an entropy measure which refers to the Shannon entropy of the probability $p(l)$, and is defined as:

$$
E N T R=-\sum_{l=l_{\min }}^{N} p(l) \ln p(l)
$$

This is a measure of the complexity of the recurrence plot. High values of $R R(t)$ indicate a high probability of occurence of the same state in both systems, and high values of $D E T(t)$ and $L(t)$ indicate a long time span for these common dynamics.

v) laminarity, which is defined as:

$$
L A M=\frac{\sum_{v=v_{\min }}^{N-t} v P_{t}(v)}{\sum_{v=1}^{N-t} v P_{t}(v)}
$$

This is a measure of tangential motion, and refers to the distributions of the vertical line lengths in the recurrence plot, which can be written as $P_{t}(v)$, analogous to the diagonal lines in the plot. where high values of $L A M$ denote motions that are not opposite in direction of trajectory but are not similar in direction either. 
vi) trapping time, which is defined as:

$$
T T=\frac{\sum_{v=v_{\min }}^{N-t} v P_{t}(v)}{\sum_{v=v_{\min }}^{N-t} P_{t}(v)}
$$

This refers to the average length of these vertical line segments and is analogous to $L(t)$ above.

\subsection{Data embedding}

Two parameters need to be determined for recurrence plot analysis, namely $m$ and $\tau$, the embedding and time delay parameters ${ }^{4}$. Kyrtsou and Vorlow (2005) set these two parameters to be 1 in all their recurrence plots, following ?) who suggests that experimental data does not need to be embedded. In terms of setting the radius parameter, $\varepsilon$, they follow Webber and Zbilut (1994) and set a threshold level of the lower $10 \%$ of the maximum distance between the embedded vectors. As Kyrtsou and Vorlow (2005) analysed only consumer prices, industrial production, interest rates and unemployment, more traditional methods for setting embedding and time delay parameters are used here. Embedding parameters are determined by the method of false nearest neighbors and the delay by the mutual information, and the results displayed in table 1 for the euro area member states and table 2 for non-euro area countries and the euro area aggregate.

\begin{tabular}{|c|c|c|c|c|c|c|c|c|c|}
\hline & B E & D K & F I & F R & GE & IT & L U & NE & SP \\
\hline $\mathrm{m}$ & 4 & 4 & 5 & 4 & 4 & 4 & 6 & 4 & 4 \\
\hline$\tau$ & 1 & 1 & 1 & 1 & 1 & 1 & 1 & 1 & 1 \\
\hline
\end{tabular}

Table 1: Embedding and time delay parameters for Euro area countries

\begin{tabular}{|c|c|c|c|c|}
\hline & $\mathrm{SW}$ & $\mathrm{UK}$ & $\mathrm{EU}-12$ & $\mathrm{US}$ \\
\hline $\mathrm{m}$ & 3 & 5 & 4 & 4 \\
\hline$\tau$ & 1 & 1 & 1 & 1 \\
\hline
\end{tabular}

Table 2: Embedding and time delay parameters for non euro area countries

Given the results above, an embedding parameter of 4 with a time delay of 1 is used in all that follows.

\section{Cross recurrence analysis for the US vs the euro area}

To establish that recurrence analysis detects some of the stylized features of business and growth cycles, cross recurrence analysis for the US and the euro area is first used to see if the international propagation of cycles is evident in the data.

The plot in figure $4^{5}$ has several notable features. First, the wide vertical spaces in the 1970 s up until the 1980s, indicates different growth rates throughout much of this period. Second, starting in roughly

\footnotetext{
${ }^{4}$ All the empirical research done in this paper was done using Norbert Marwan's CRP MATLAB toolbox.

${ }^{5}$ In the upper part of the figure the black line refers to US economic growth and the red line to euro area economic growth, while in the lower part of the figure the horizontal axis refers to US growth and the vertical axis to euro area growth.
} 

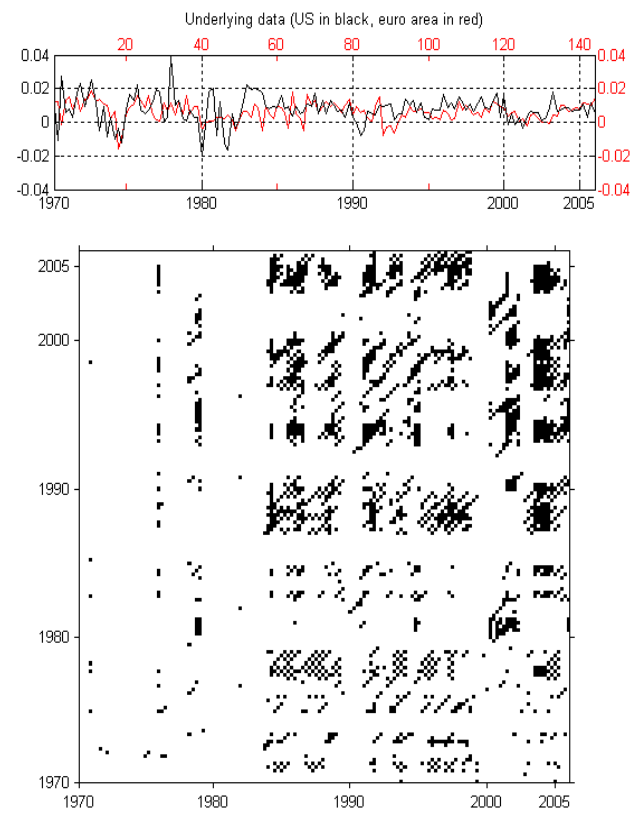

Figure 4: Cross recurrence plot for euro area aggregate vs US with threshold of 0.009 using euclidean distance with non-normalised data.

1983 a marked increase in recurrence for the US that was mirrored by a similar increase in the euro area aggregate from roughly 1987 onwards. Third, in the upper right-hand part of the cross recurrence plot, there are indications of non-phased synchronous movements in growth rates, with the euro area tending to lag those of the US. It is clear from figure 4 that some movements in economic growth are highly correlated ( - particularly in the 1970s) and yet these do not show up on a thresholded plot, so an unthresholded plot is also shown in figure 5

In figure 5 yellow diagonal lines can be seen during the 1970s indicating synchronicity but little convergence in growth rates between the US and the euro area during this period. The other feature of the recurrence distance plot is that because of the propagation effects these vertical and horizontal bands often coincide with US recessions (as in 1974, 1981, 1991 and 2001). From the late 1980s onwards though there appears to be dark blue lines above the leading diagonal which suggests phased synchronicity between the US and the euro area, with the euro area lagging against the US. The cross recurrence quantification analysis appears in figure 6 and confirms these observations, with an increase in recurrence rates in the mid-1980s onwards but with the average diagonal line length not increasing since this period, indicating no increase in common dynamics over this period. These results tend to suggest that the propagation of business cycles across the Atlantic has not increased significantly in the last two decades. 

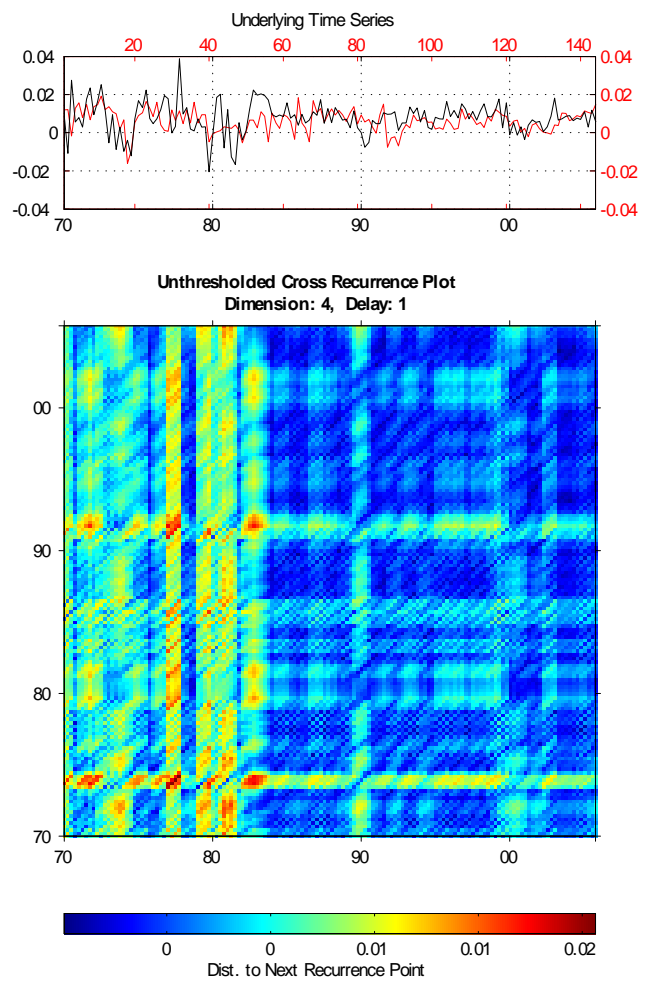

Figure 5: Cross recurrence plot for euro area aggregate vs US, unthresholded using euclidean distance with non-normalised data. 

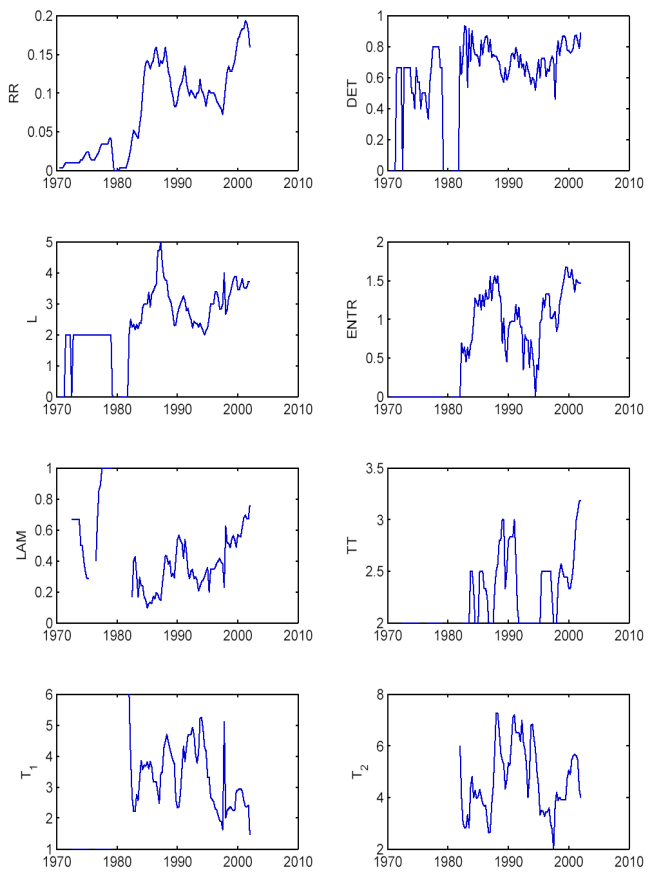

Figure 6: CRQA for the euro area vs US growth.

\section{Cross recurrence analysis for selected EU member states}

In the euro area, as there is a single monetary policy, there are two desirable features in economic growth dynamics:

a) synchronicity - this indicates that monetary policy is acting on business cycles that are similarly phased and in the recurrence plot context is measured by the length of diagonal lines at or near the leading diagonal. Given two variables, $x_{t}$ and $y_{t}$, then in mathematical terms:

$$
\varphi\left(x_{t}\right)-\varphi\left(y_{t}\right) \leq \pm \omega
$$

where $\varphi$ is a phase function and $\omega$ represents a critical phase shift.

b) convergence - this indicates that the nominal interest rates implicit in monetary policy are having a similar impact on economic growth (through the transmission mechanism of monetary policy) across the euro area. In a recurrence quantification context this is indicated by the recurrence measure. In mathematical terms:

$$
d(x-y) \leq \varepsilon ; \forall t
$$

where $d$ is the distance function and $\varepsilon$ is some critical distance. 


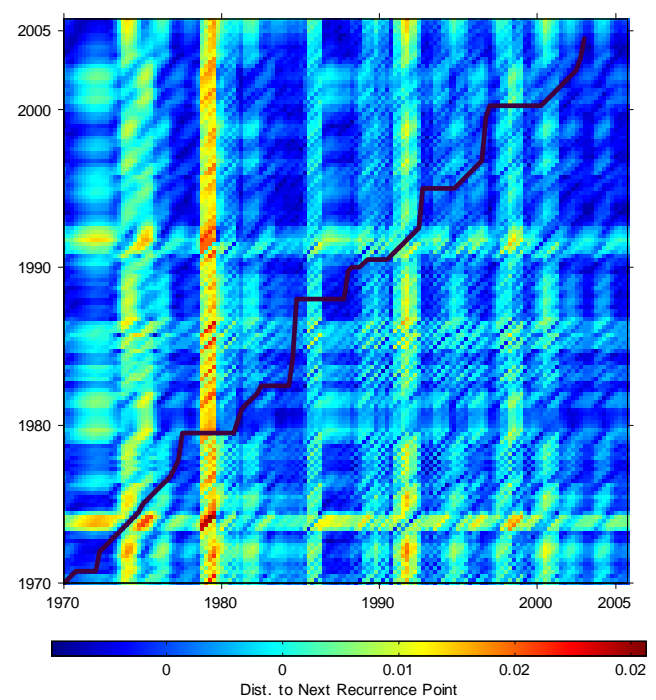

Figure 7: Unthresholded cross recurrence plot for Belgium vs euro area growth rates.

The degree of synchronicity and convergence within the core of the euro area is first analysed, and then those in the periphery of the euro area (which have smaller weights in the euro area aggregate - for example Ireland, Greece and Finland) are analysed. Lastly for those outside of the euro area (such as the UK), the objective is to see if synchronicity and convergence have increased or decreased. As both recurrence and synchronicity are relevant, both thresholded and non-thresholded plot are used in what follows, dependent on how clear the dynamic features are with thresholded plots.

As there are 15 countries in the European Union, plots and quantification analysis are presented for a selection of member states (determined by importance and data availability), representing those member states who are in the core of the euro area, those on the periphery and those that have yet to join.

\subsection{Core euro area member states}

In the case of Belgium, in figure $7^{6}$ there is a clear line of synchronicity ( - a darkened leading diagonal) where a line of synchronicity has been plotted using the algorithm from Marwan, Thiel, and Nowaczyk (2002) to show when growth rates were synchronised. With the exception of the late 1970s and mid 1980s, there is a clearly no phasing in growth. Laminar areas have appeared from around 2003 indicating convergence in growth rates with the euro area aggregate ${ }^{7}$.

The main feature to note in the Belgian cross recurrence analysis in figure 8 is that the recurrence rate appears to have increased since the inception of EMU in 1999, indicating increased convergence, which

\footnotetext{
${ }^{6}$ Here the horizontal axis refers to Belgian growth and the vertical axis refers to euro area growth.

${ }^{7}$ This is more clearly shown in the thresholded plot, but unfortunately the line of synchronicity doesn't appear as clearly in this version of the plot.
} 

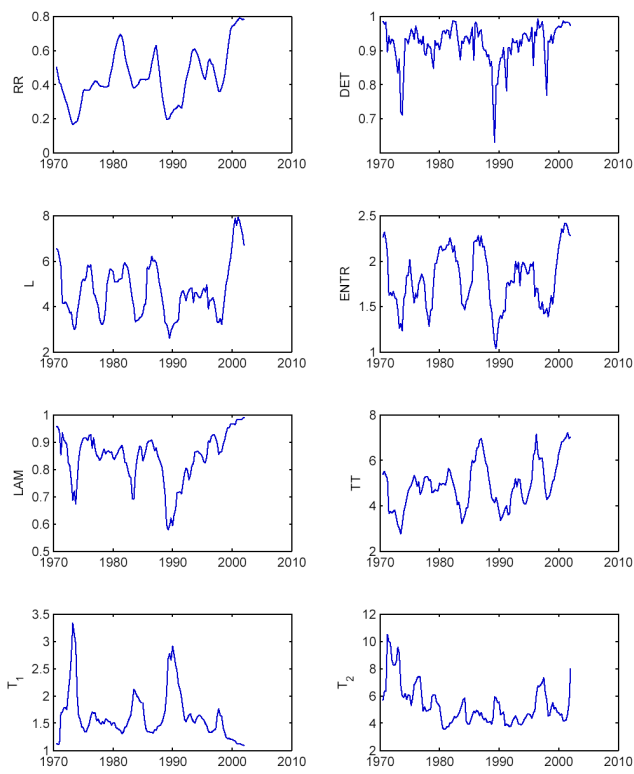

Figure 8: CRQA for Belgian vs euro area growth.

tends to suggest similar dynamic features appear in both time series. $L$, the average diagonal length has also increased significantly, indicating increased synchronicity since 1999. The laminarity rate has also increased, indicating that growth and business cycles have been damped in recent years.

Turning to the French recurrence plot in figure 9 here a low threshold is used to show the diagonal structures in the plot, with a plotted line of synchronicity in blue clearly running up the leading diagonal. There is a definite square shape in the top right hand corner of the plot indicating much greater recurrence occurring after 1992 when the timetable for completing the convergence criteria for joining the euro area were put in place. The line of synchronicity strays from the leading diagonal in the early 1980s, and the most recent data appears to show that this dynamic might be reoccurring.

The main features of the CRQA for France in figure 10 are similar to those of Belgium here, but a regime change is less apparent in 1999 when the euro was introduced. The recurrence rate increased in the early 1990s but laminarity continued to increase throughout the 1990s. The measure of diagonal line length increased during the second half of the 1990s but has fallen in the post-1999 period indicating lower commonality of economic growth dynamics.

Figure 11 shows the cross recurrence plot for German real GDP growth. Here the nature of the synchronicity is less consistent than with France. There are both synchronous periods and then also periods when no synchronicity is apparent (for example around 1980 and in the early 1990s) or a shift in phase occurs (as in the late 1990s). Nevertheless, from 1999 onwards, synchronicity appears to have been 


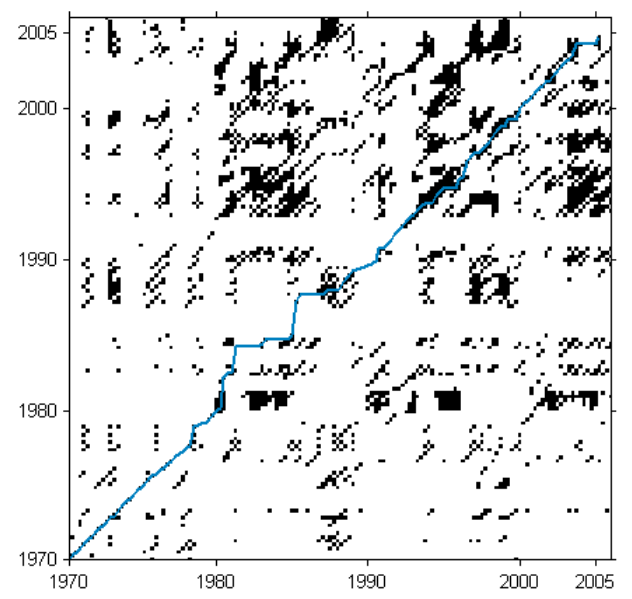

Figure 9: Thresholded cross recurrence plot for French vs euro area growth rates $(\varepsilon=0.0075)$.
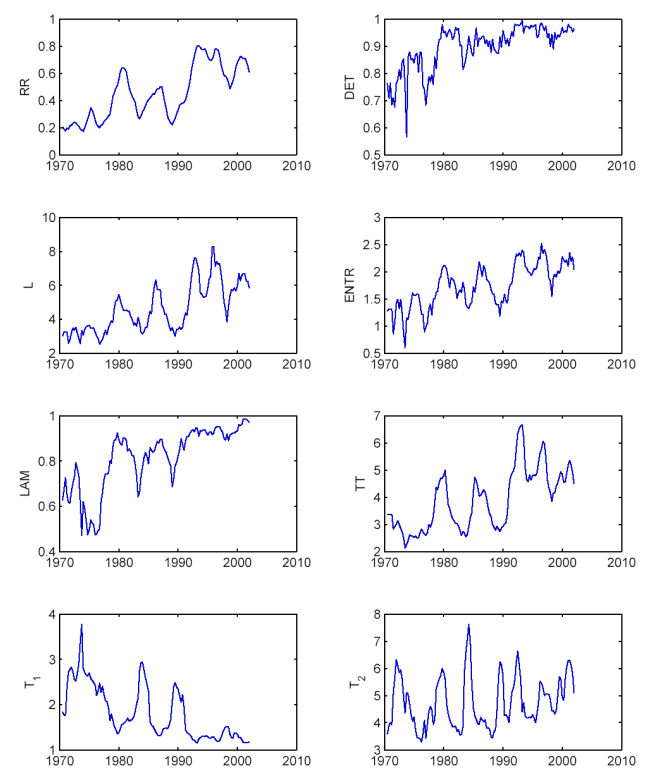

Figure 10: CRQA for French vs euro area growth. 


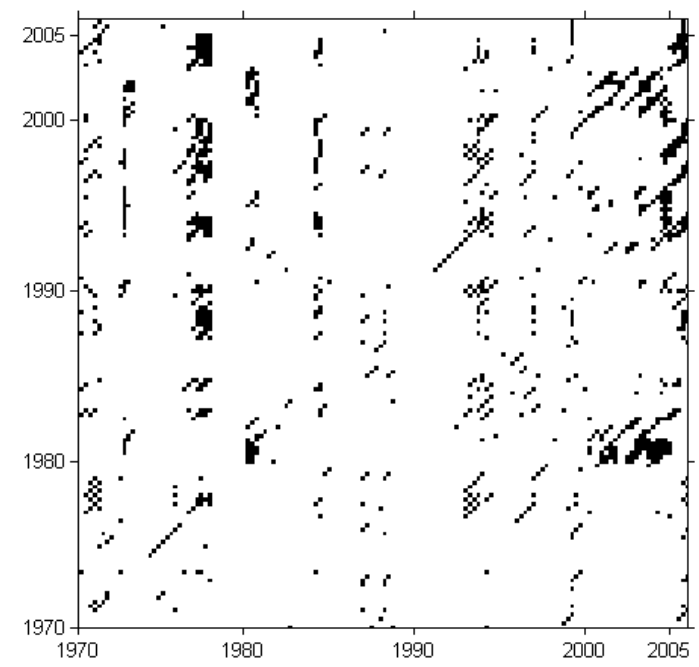

Figure 11: Thresholded cross recurrence plot for German vs euro area growth rates $(\varepsilon=0.0075)$.

present, although around 2003 a definite phase shift appears to have occurred.

These observations also inform the recurrence quantification plots in figure 12. For the 5 year window beginning in 1989 recurrence, average diagonal length and determinism falls to zero and then rapidly recover as the window moves forward in time: other quantities such as laminarity and trapping time actually suffer a discontinuity at this point. This is not entirely surprising given that German reunification occurred in 1989, but it is notable that even using a spliced series for Germany pre- and post-1999 recurrence plot analysis clearly identifies this breakpoint. Since 1995 the recurrence rate has risen showing greater convergence with the euro area aggregate, and L has also increased reflecting the non-phase synchronous movements in growth.

\subsection{Peripheral euro area member states}

Now we turn to the case of peripheral euro area member states. For Finland, in figure 13 the major recession in the early 1990s is clearly notable in terms of the yellow vertical band across the plot. The most recent data used in this study appears to suggest that these was a divergence in growth rates after a period of increased synchronisation in the early years of EMU. The recurrence quantification plots (which are shown in figure 14) show an increase in recurrence over time with a peak reached for the 1995-2000 window, but these recurrence rates are still at very low levels compared with France for example where the maximum is at roughly 0.6 .

On the other hand, Spanish real GDP growth has been relatively synchronous with euro area real GDP 

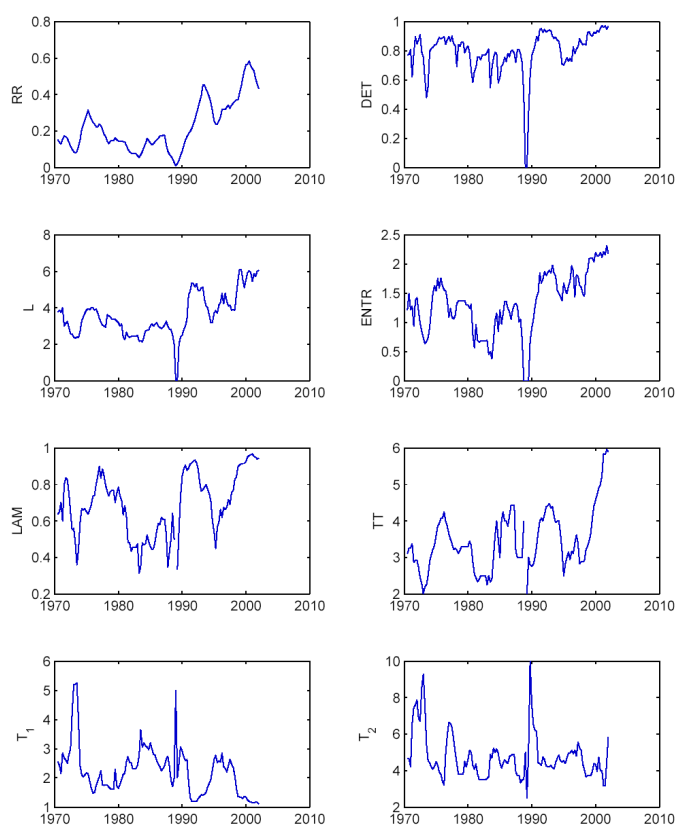

Figure 12: CRQA for German vs euro area growth.
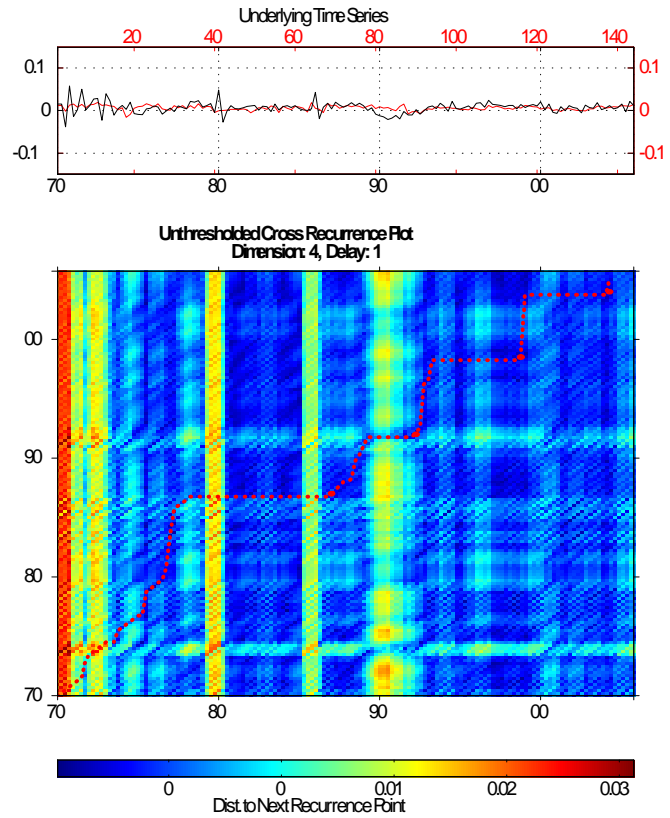

Figure 13: Unthresholded cross recurrence plot for Finland vs euro area growth rates. 

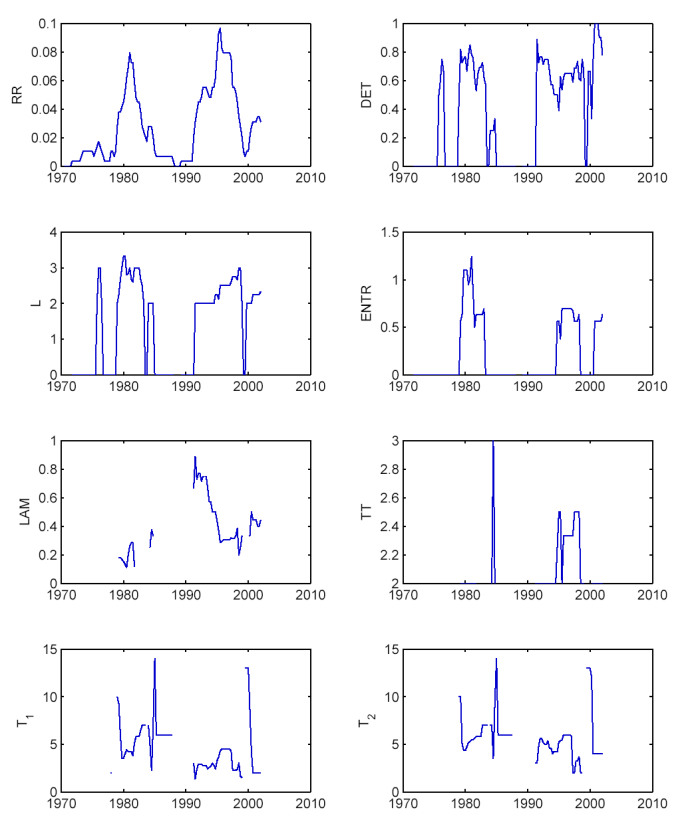

Figure 14: CRQA for Finland vs euro area growth.

growth from 1990 through until 2001, but more recently growth rates appeared to have diverged. Figure 15 uses a wider radius parameter than for core euro area member states and although recent dynamics have been laminar in nature, recurrence has continued to increase as well as the average line length signifying synchronicity as well as an increased level of convergence.

\subsection{Non-euro-area EU member states}

For non euro area countries or member states, cross recurrence plots are constructed against euro area real GDP growth rates. The UK is an EU member state, but (like Sweden and Denmark), has a derogation from EMU. Nevertheless, the UK government has made a commitment to join the euro area "when the time is right". One of the conditions for membership of the euro area is phase-synchronous business cycles, but in the last assessment of this (in 2004) the verdict was that UK growth is not phase-synchronous with euro area growth. Figure 17 indeed suggests that this assessment was correct, although there appears to be some intermittent synchronicity with the UK leading the EU growth rate dynamic. Nevertheless as figure 18 clearly shows, recurrence rates are much higher than in the 1970s or 1980s, showing that a certain degree of convergence has occurred. 


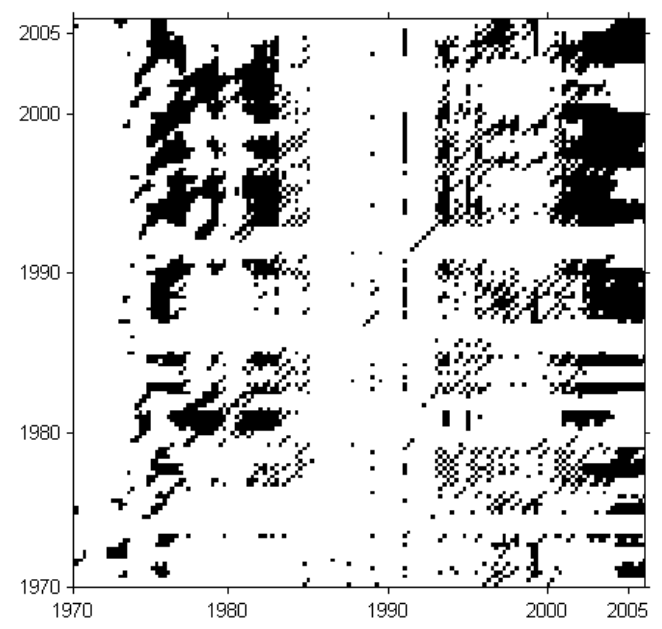

Figure 15: Thresholded cross recurrence plot for Spanish vs euro area growth rates $(\varepsilon=0.01)$.
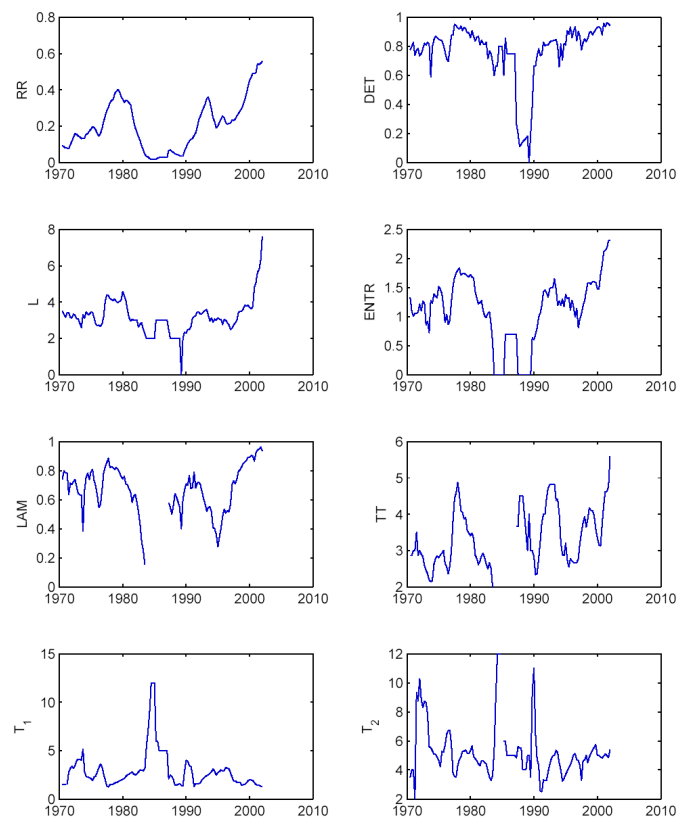

Figure 16: CRQA for Spain vs euro area growth. 

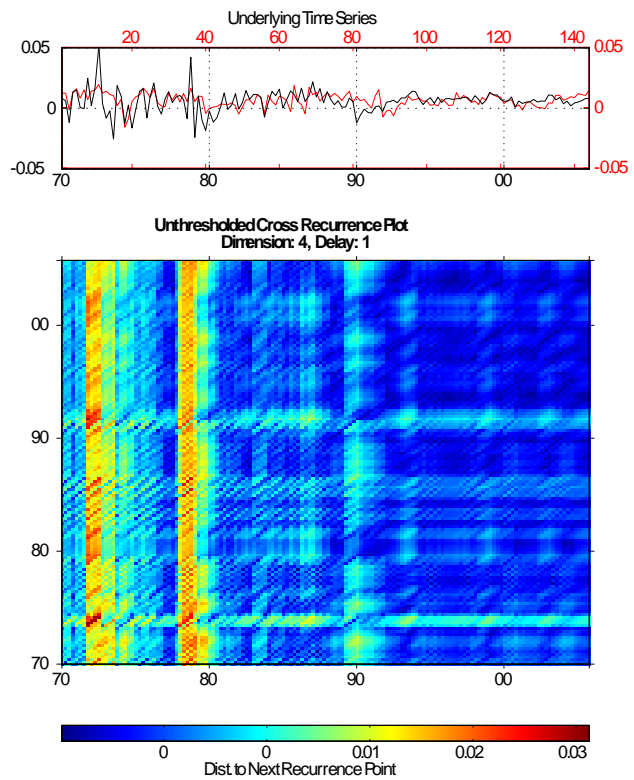

Figure 17: Unthresholded cross recurrence plot for UK vs euro area growth.
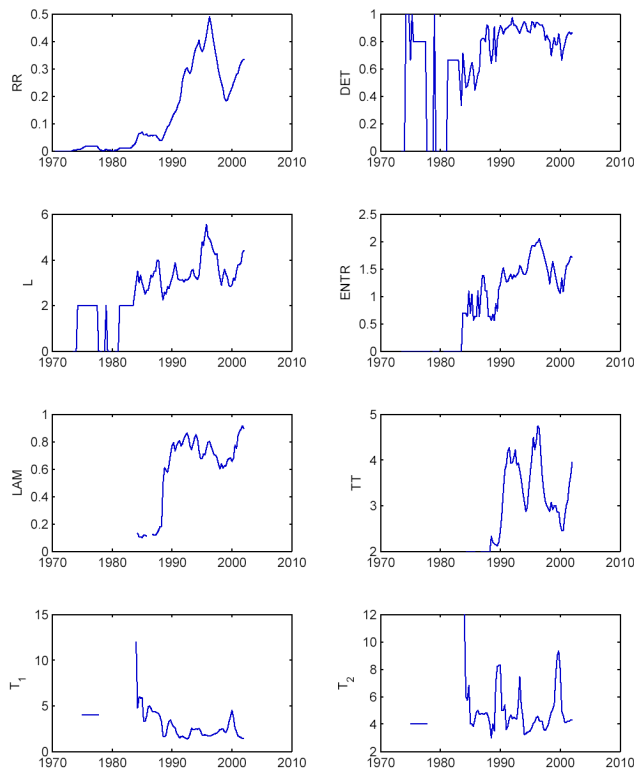

Figure 18: CRQA for UK vs euro area growth. 


\section{Is lack of convergence and/or phase-synchronicity a problem for the ECB?}

With a single monetary policy there are four possible outcomes for convergence and synchronisation of real GDP growth rates:

i) both convergence and (either full or intermittent) synchronisation (e.g. Belgium, France, Germany, Italy, Spain)

ii) converged but not synchronized (e.g. Finland, Netherlands, UK);

iii) not converged but synchronized (e.g. Sweden); and

iv) neither converged nor synchronized (e.g. US).

Although this is admittedly a rough classification, it shows that there are some member states which are better suited to the ECB's monetary policy than others, and this will obviously imply a differential impact across the euro area. One of the interesting features of this result is that the "core vs periphery" distinction (made by Artis and Zhang (1997)) is not as clear cut as it was in the 1990s - one core member state (Netherlands) is not grouped with the other core member states, and one peripheral member state (Spain) is.

Given this classification of growth and business cycles in relation to the euro area aggregate there are three important questions that are relevant for ECB policy:

a) is convergence sufficient for ECB monetary policy to be optimal or is a reasonable degree of synchronicity necessary?;

b) is intermittent synchronicity a potential problem for ECB monetary policy?

c) are recent trends in the euro area core indicative of a change in regime occurring in late 2005 ?

The first question asks whether ECB monetary policy could prove wholly inappropriate for some member states if synchronisation is not achieved, which in turn could lead to problems for the long term sustainability of the euro area. According to OCA theory, convergence is not a sufficient condition so non-phase synchronised member states might eventually decide to either leave the euro area or insist on an implementation of supra-national policies to counter a non-optimal monetary policy.

The second question applies to certain member states (such as Germany) where there are intermittent periods where synchronous growth dynamics are absent. If these are due to asymmetric "shocks" hitting the system, which cause divergence for a short period of time then this is only a short-term problem, but 
if this is a systematic and repetitive dynamic then this could be problematic for ECB monetary policy at some point in the future.

The third question points to some worrying developments in the most recent data, which shows that the core of the euro area appears to have diverged from the growth rates experienced by the average euro area member ( - represented by the euro area aggregate). This could be a temporary divergence ( - a differential response to the US slowdown, for example), but also it could be more permanent and represent a change in regime.

\section{Conclusions}

Cross recurrence plots and quantification analysis offers a unique non-linear approach to studying economic time series and their interaction over time. There are few existing studies of macroeconomic dynamics which utilize this methodology, and so the application in this contribution serves to illustrate the potential for this methodology in the study of macroeconomic dynamics and policy analysis.

In this paper the nature of international propagation of business and growth cycles between the euro area and the US was first considered, and the findings were that although propagation has clearly increased in the 1980s, there has been no significant change since then. In terms of phasing of synchronous episodes, the euro area clearly lags behind the US. Next, cross recurrence plots were used to analyse real GDP growth between a euro area growth aggregate and a sample of European member states. Synchronicity and convergence was found to be high between most of the core euro area member states, suggesting that monetary policy is not having a major differential impact on these countries and that they are increasingly suited to being part of a monetary union. Both inside and outside of this core, however, there is no consistency for many member states in terms of their synchronicity or convergence onto the euro area growth rate. This should clearly be a concern for the future membership of the euro area, and might

decrease the public perceptions of the desirability of being part of the euro area in these countries in the future.

In terms of the study of non-linear dynamics, there is ample scope for further research: first, the relationship between convergence and synchronisation is clearly of interest in this context, and secondly the intermittent synchronisation observed for several of the member states in this study also merits further investigation.

\section{References}

Altavilla, C. (2004). Do EMU members share the same business cycle? Journal of Common Market Studies 42(5), 869-896. 
Artis, M. and W. Zhang (1997). International business cycle and the ERM: Is there a european business cycle? International Journal of Finance and Economics 2, 1-16.

Artis, M. and W. Zhang (1999). Further evidence on the international business cycle and the ERM: Is there a european business cycle? Oxford Economic Papers 51, 120-132.

Backus, D. and P. Kehoe (1992). International evidence on the historical properties of business cycles. American Economic Review 82, 864-888.

Backus, D., P. Kehoe, and F. Kydland (1995). International business cycles: Theory and evidence. In F. Cooley (Ed.), Frontiers of Businss Cycle Research, pp. 331-356. Princeton, NJ, USA: Princeton University Press.

Crivellini, M., M. Gallegati, M. Gallegati, and A. Palestrini (2004). Industrial output fluctuations in developed countries: A time-scale decomposition analysis. Working Papers and Studies: Papers from the 4th Eurostat and DGFin Colloquium "Modern Tools for Business Cycle Analysis", European Commission, Brussels, Belgium.

Crowley, P. and J. Lee (2005). Decomposing the co-movement of the business cycle: A time-frequency analysis of growth rates in the euro area. Bank of Finland, Helsinki, Finland. Discussion paper $12 / 2005$.

De Haan, J., R. Inklaar, and O. Sleijpen (2002). Have business cycles become more synchronized? Journal of Common Market Studies 40(1), 23-42.

Eckmann, J.-P., S. Kamphorst, and D. Ruelle (1987). Recurrence plots of dynamical systems. Europhysics Letters 5, 973-977.

Feller, W. (1950). An Introduction to Probability Theory and its Applications, Vol. New York, NY, USA: John Wiley Sons.

Frankel, J. and A. Rose (1998). The endogeneity of optimal currency area criteria. The Economic Journal 108(449), 1009-25.

Kontolemis, Z. (1997). Does growth vary over the business cycle? some evidence from the $<\mathrm{g} 7>$ countries. Economica 64 (255), 441-460.

Kyrtsou, C. and C. Vorlow (2005). Complex Dynamics in Macroeconomics: A Novel Approach, Chapter 11, pp. 223-238. Springer, NY, USA.

Marwan, N., C. Romano, M. Thiel, and J. Kurths (2007). Recurrence plots for the analysis of complex systems. Physics Reports 438, 237-329.

Marwan, N., M. Thiel, and N. Nowaczyk (2002). Cross recurrence plot based synchronization of time series. Nonlinear Processes in Geophysics 9, 325-331. 
Mundell, R. (1961). A theory of optimum currency areas. American Economic Review 51, 509-17.

Sensier, M., M. Artis, D. Osborn, and C. Birchenhall (2004). Domestic and international influences on business cycle regimes in europe. International Journal of Forecasting 20, 343-357.

Süssmuth, B. (2002, January). National and supranational business cycles (1960-2000): A multivariate description of central g7 and euro15 NIPA aggregates. CESifo Working Paper 658(5).

Takens, F. (1981). Detecting Strange Attractors in Turbulence, Volume 898 of Lecture Notes in Mathematics: Dynamical Systems and Turbulence, Warwick 1980, pp. 366-381. Springer-Verlag, Berlin, Germany. D. Rand L.-S. Young (eds).

Valle e Azevedo, J. (2002, April). Business cycles: Cyclical comovement within the european union in the period 1960-1999. a frequency domain approach. WP 5-02, Banco do Portugal, Lisbon, Portugal.

Webber, C. J. and J. Zbilut (1994). Dynamical assessment of physiological systems and states using recurrence plot strategies. Journal of Applied Physiology 76, 965-973.

Webber Jr., C. and J. Zbilut (2005). Recurrence quantification analysis of nonlinear dynamical systems. National Science Foundation, Washington DC, USA. Chapter 2, Methods for the Behavioral Sciences, eds. M. Riley and G. Van Orden, available at www.nsf.gov/sbe/bcs/pac/nmbs/nmbs.jsp.

Zarnowitz, V. and A. Ozyildirim (2002, January). Time series decomposition and measurement of business cycles, trends and growth cycles. Working Paper 8736, NBER, Cambridge, MA, USA.

Zbilut, J. (2005). Use of recurrence quantification analysis in economic time series. In M. Salzano and A. Kirman (Eds.), Economics: Complex Windows, pp. 91-104. Milan, Italy: Springer-Verlag Italia.

Zbilut, J. and C. Webber Jr. (1992). Embeddings and delays as derived from quantification of recurrence plots. Physics Letters A 171, 199-203. 